\title{
A Pilot Study of Utilization of Blood Components at Tertiary Care Centre, Rajkot
}

\author{
Shruti K . Katkoria, Amit H. Agravat* and Gauravi A. Dhruva \\ Department of Pathology, Pandit Deendayal Upadhyay Government Medical College, Rajkot, India
}

\section{ABSTRACT}

Background: Blood is essential for life. It contains cellular component and plasma which supplies oxygen, nutrients to different parts of the body. Transfusion of blood and blood components is an integral part of health care practice. Many a times there will be injudicious use of blood and its products among patients which causes unnecessary burden to the patients as well to blood bank. Main aim of this study is to evaluate the pattern of utilization of blood components in tertiary care hospital at Rajkot.

Methods: This was retrospective study carried out over a period of 1 year from January 2017 to December 2017. All the data were collected from blood bank.

Result: Total number of the blood components utilized in the year 2017 was 22290. The most utilized blood component included of Red Cell Concentrate (RCC) followed by Fresh Frozen Plasma (FFP) and Platelet Concentrate respectively. Cryoprecipitate was least utilized component. Thalassemia ward was majorly benefited.

Conclusion: Periodic evaluation of utilization pattern, demand for different blood products also helps to maintain the blood stock.

\section{Keywords: Components, Red Cell Concentrate, Fresh Frozen Plasma, Utilization}

\section{Introduction}

Blood is a specialized bodily fluid that supplies essential substances and nutrients and removes metabolic waste products from the cells. The cellular components include red blood cells, white blood cells, platelets and cryoprecipitate. Plasma contains coagulation factors. Blood is essential for human survival. ${ }^{[1-3]}$ Blood component therapy has gained much of the interest in recent years because of its merits over whole blood transfusion like, it reduces volume overload on patient and has greater shelf life, better patient management. Component therapy was introduced between 1950s and 1960s to maximize the benefits of all components present in the whole blood ${ }^{[5]} \mathrm{In}$ developing countries there are limited resources of blood and increasing demand, and hence it is necessary to make an efficient use of blood. As blood is a scarce resource, clinician should weigh the risks of transfusion against risks of not transfusing. Primary Goal of blood centers and transfusion services is to promote high standards of quality in all aspects of production, patient care, and service. Evaluation of pattern of blood component usage, its demand and good audit management is needed to ensure appropriate utilisation of precious resource. ${ }^{[1]}$

Transfusion audits provide a review of policies and practices to ensure safe and appropriate transfusions and are based on measurable, predetermined performance criteria.
Transfusion services should investigate an adequate sampling of cases Audits assess the facility's performance and effectiveness in:

- Blood ordering practices for all categories of blood and components.

- Minimizing wastage of blood components

- Distribution, handling, use, and administration of blood components.

- Evaluating all confirmed transfusion reactions.

- Meeting patients' transfusion needs.

- Informing patients and physicians in a timely and confidential manner of possible infectious disease transmission[13]

\section{Materials and Methods}

Present study was a retrospective study carried out in our Blood Bank, at P.D.U. Hospital Rajkot over a period of 1 year from January 2017 to December 2017. We collected data of monthly collection and utilisation of blood components from the record books in the blood bank. Details of components issued are documented in the blood bank registers. It included cross matched and issued blood units. Data also included age, gender, diagnoses of transfusion recipients and the department which utilized it like Medicine, Labour Room, Gynaecology, Surgery, Orthopaedics etc. 
We also recorded indication of component transfusion to the patient, number of components demanded by the clinicians, number of transfusion episodes for all patients and branch/specialty of medicine by which the components were demanded from blood requisition forms. The usage of different types of components was recorded and correlated with the patient's diagnosis and indications for transfusion.

\section{Result}

The total number of units issued in the year 2017 was 22290 out of which RCC was 17468 followed by FFP 3706 and Platelet Concentrate 961.Cryoprecitate was the least utilized component only 155 units in entire year. Thalassemia and medicine ward were majorly benefitted with red cell concentrate. As shown in Figurel the demand of components is more in female as compared to male. Maximum number of components issued were of $\mathrm{B}$ positive. The requirement of components was majorly observed in the age group of 13 to 30 years. Least number of component requirement was seen in ENT department. The most common indication of transfusion in labour room was Post-Partum Haemorrhage and Abruptio placenta followed by blood loss in procedure. In SURGERY and ORTHOPEDICS, the most common indication of utilization of component was polytrauma leading to blood loss and hypovolemia. In MEDICINE maximum RCC were utilized for Thalassemia patients and FFP were utilized for patient with liver disorders and coagulopathies. Paediatric patients were having sepsis and anaemia as the main indication for transfusion of the blood components. Aaeamia continues to be the most common indication of transfusion.

Table 1: Showing Number of Units of Different Components.

\begin{tabular}{|c|c|c|}
\hline COMPONENT & NUMBER OF UNITS & Percentage \\
\hline Red Cell Concentrate & 17468 & $78.36 \%$ \\
\hline Fresh Frozen Plasma & 3706 & $16.62 \%$ \\
\hline Platelet Concentrate & 961 & $4.31 \%$ \\
\hline Cryoprecipitate & 155 & $0.71 \%$ \\
\hline Total & $\mathbf{2 2 2 9 0}$ & $\mathbf{1 0 0 \%}$ \\
\hline
\end{tabular}

Table 2: Depicting The Group Wise Utilization of Different Components.

\begin{tabular}{|c|c|c|}
\hline GROUP & NUMBER OF UNITS & $27.92 \%$ \\
\hline A Positive & 6250 & $30.84 \%$ \\
\hline B Positive & 6963 & $27.01 \%$ \\
\hline O Positive & 6181 & $7.44 \%$ \\
\hline AB Positive & 1676 & $1.5 \%$ \\
\hline A Negative & 344 & $2.65 \%$ \\
\hline B Negative & 597 & $2.50 \%$ \\
\hline O Negative & 564 & $0.68 \%$ \\
\hline AB Negative & 155 & $\mathbf{1 0 0 \%}$ \\
\hline TOTAL & $\mathbf{2 2 2 9 0}$ & \\
\hline
\end{tabular}

Table 3: Comparative Study of Blood Components at Different Centres.

\begin{tabular}{|c|c|c|c|}
\hline & Present Study (2017) & KIMS,Hubli $^{[4]}(\mathbf{2 0 1 5 )}$ & SAQR hospital,UAE(2011) ${ }^{[9-10]}$ \\
\hline Total number of units issued & 22290 & 12555 & 7045 \\
\hline$\%$ of red cell concentrates & $78.36 \%$ & $43.77 \%$ & $49.25 \%$ \\
\hline$\%$ of fresh frozen plasma & $16.66 \%$ & $36.69 \%$ & $25.55 \%$ \\
\hline$\%$ of Platelets & $4.3 \%$ & $19.52 \%$ & $18.45 \%$ \\
\hline$\%$ of cryoprecipitate & $0.69 \%$ & $0 \%$ & $8.16 \%$ \\
\hline$\%$ of Female recipients & $53.33 \%$ & $61.81 \%$ & $52 \%$ \\
\hline$\%$ of male recipients & $46.67 \%$ & $38.19 \%$ & $48 \%$ \\
\hline
\end{tabular}


Table 4: Comparative Study of Components by Different Departments at Different Centres.

\begin{tabular}{|c|c|c|c|}
\hline Diagnoses & Present Study & KIMS,Hubli[4] & SAQR hospital,UAE ${ }^{[9-10]}$ \\
\hline Surgery & $10.12 \%$ & $16.07 \%$ & $33 \%$ \\
\hline Labour room & $13.27 \%$ & 13.94 & $7 \%$ \\
\hline Gynecology & $4.78 \%$ & $20.50 \%$ & $4 \%$ \\
\hline Orthopedics & $8.65 \%$ & $18.97 \%$ & $27 \%$ \\
\hline Peadiatrics & $11.55 \%$ & $11.48 \%$ & $12 \%$ \\
\hline Medicine & $50.93 \%$ & $18.32 \%$ & $16 \%$ \\
\hline ENT & $0.66 \%$ & $0.74 \%$ & $1 \%$ \\
\hline
\end{tabular}

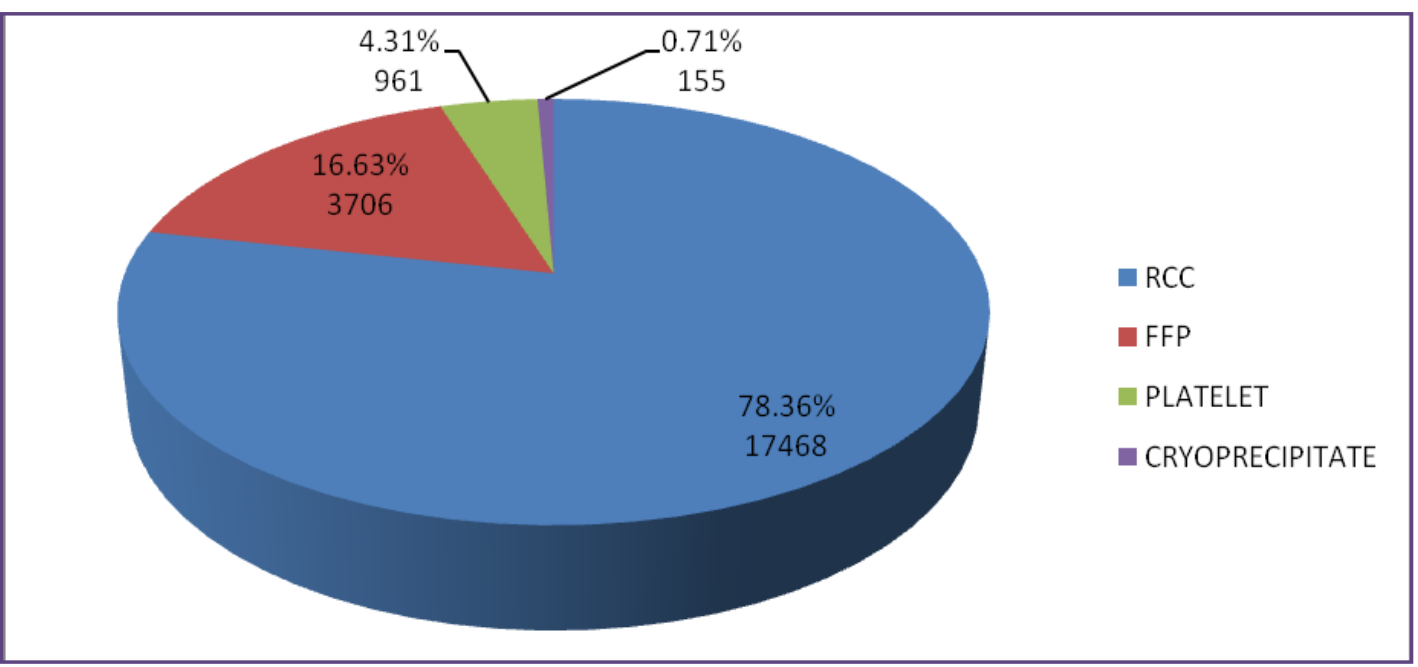

Fig. 1: Depicting The Distribution of Utilization of Various Blood Components.

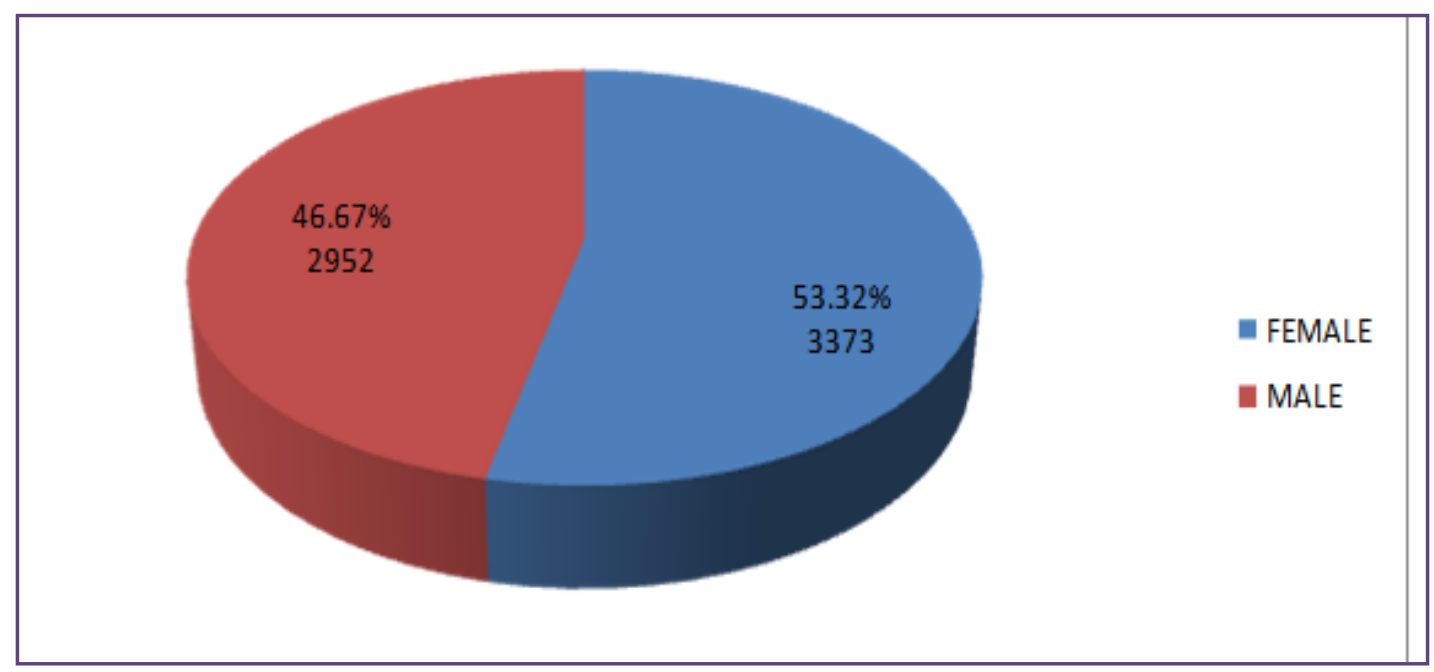

Fig. 2: Gender Wise Distribution of Transfusion Recipients. 


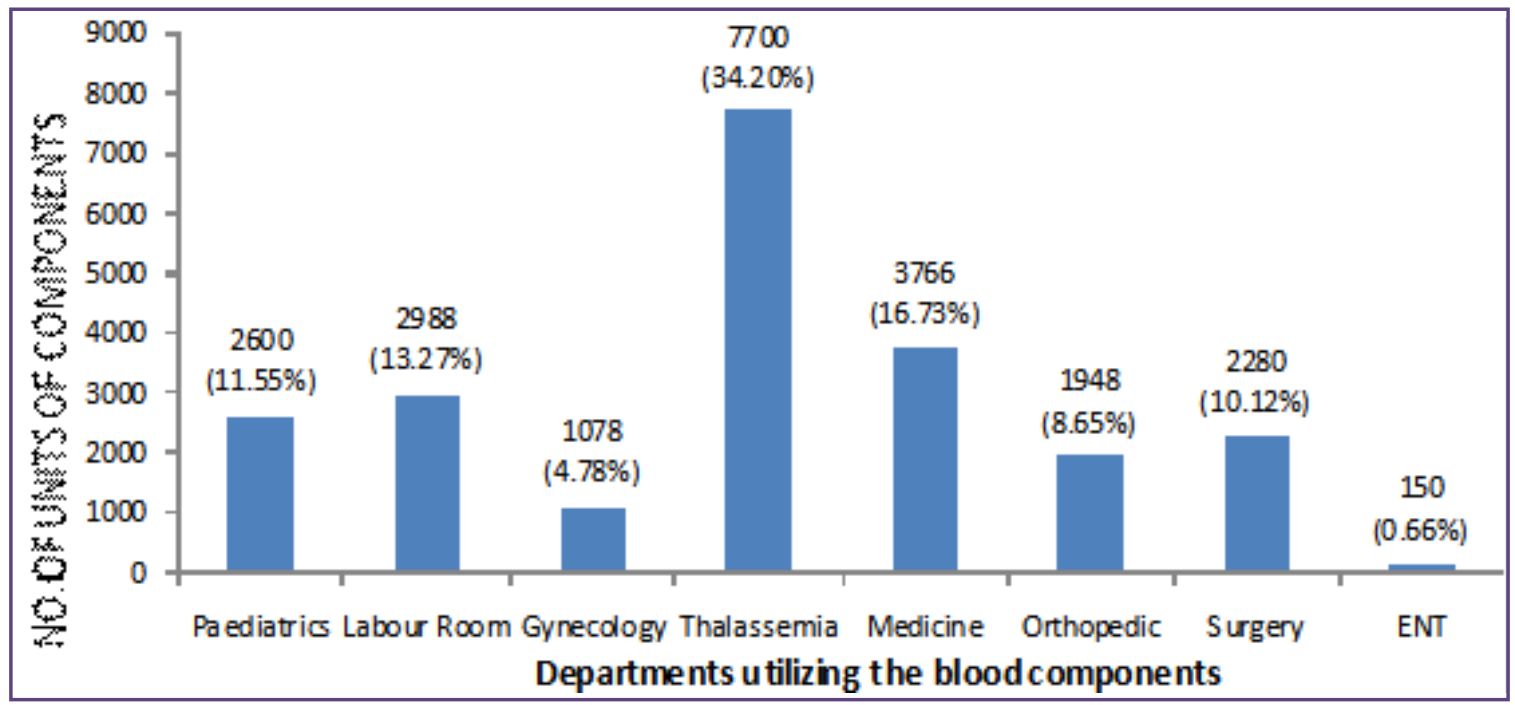

Fig. 3: Showing Utilization of The Blood Components by Different Departments.

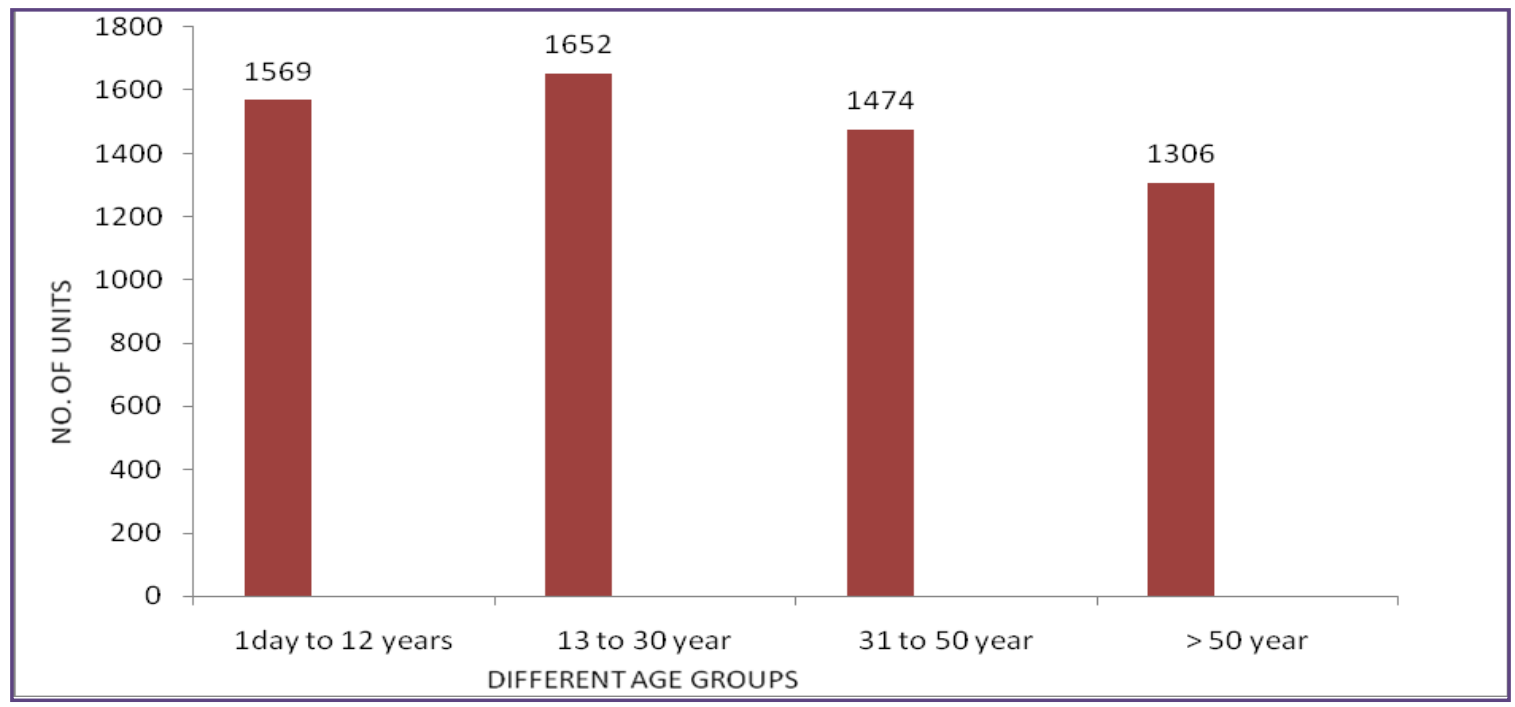

Fig. 4: Column Graph Showing No. of Blood Components Issued in Different Age Groups.

\section{Discussion}

Blood transfusion services are vital and integral part of modern health care. In recent years the blood components utilization has been increasing due to burden of chronic diseases in aging population, blood intensive surgical procedures $^{[2]}$. Effective use of blood components is important goal for blood utilization management system. Many of the recipients were given single unit transfusion. This requires proper knowledge regarding availability of the components among the clinicians. ${ }^{[5]}$ There is considerable variation in the pattern of utilization of the components among various clinical specialties and hospitals. Request were less than the number of units issued because there were many patients given more than one unit of blood.
There is a variation in utilization of the components in depending on anticipated blood loss or actual blood loss. As the actual loss might be less than the anticipated blood loss leading to excessive transfusion. The total number of components issued were 22290 of which RCC were $78.36 \%$ (17468), FFP were 16.62\% (3706), platelets were $4.31 \%$ (961) and cryoprecipitate were $0.71 \%$ (155).

As seen above in figure 2 the number of female $3373(53.32 \%)$ recipients are more than males2952(46.67\%). Of all the blood groups B positive was more in demand as per data of Table no.2

As per comparative study the pattern of utilization of components remains the same as above. The number of 
female recipients stays on a higher side in all the three studies. RCC also continues to be the most utilized product followed by FFP and Platelet Concentrate.

As per table 4 in present study maximum number of components are issued to department of Medicine where as in study carried at KIMS, Hubli maximum number of components are issued to department of Gynecology ${ }^{[4]}$ and at SAQR hospital, UAE maximum number of components are issued to department of surgery ${ }^{[9-10]}$. There is no uniformity in distribution of blood and its components according to clinical specialties. ${ }^{[5]}$ There is a variation in the pattern of utilization of the components in different institutes by different departments. In surgical cases blood and components are often ordered due to anticipated loss than actual one. This leads to overuse of blood products, wastage and unnecessary exposure of patients to various haematological antigens and infections. Hence, inappropriate use of blood and blood components should be avoided ${ }^{[6]}$.

\section{Conclusion}

This study provides information of pattern of usage of blood and blood components in our hospital. This also enables internal quality control for better functioning of blood bank. This also shows the importance of formulation and implementation of strict guidelines for transfusion practices in the hospital. This should be agreed upon by the clinicians and blood bank authorities. Thereby unnecessary usage of blood units can be controlled and effective management of blood stock can be achieved.

It is important for the blood bank to be able to fulfil the demands for this life-saving product and at the same time, evaluate and assess the existing trends of blood ordering. This is important to prevent misuse which may lead to shortage of blood availability and thus denial of blood supply to someone in a life-threatening situation

\section{Reference}

1. Mathew AS, Kurian SS, Sundaresan NP, Jayalekshmi, Roderigues FP, et al. Pattern of blood component utilization in a teaching hospital in SouthKerala. Academic Medical Journal of India 2014
2. Alcantara CJ, Opina PA, Alcanatara MR (2015) Appropriateness of use of Blood products in tertiary hospitals International Blood Research and Reviews3: 54-65.

3. Gaur SD, Negi G, Chauhan N, Kusum A, Khan S, et al. Utilization of blood and components in a tertiary care hospital. Indian J Hematol Blood Transfus 2009;25: 91-95.

4. Venkatachalapathy TS, Subhashish D. A prospective audit of blood transfusion request RL Jalappa hospital and research centre for blood and blood components. J Blood Lymph 2012; 2:106.

5. Joshi RA, Ajmera JR, Kulkarni SA, Bindu SR, Kulkarni SS. Observational study in Utilization of blood and blood products at tertiary care centre .International journal of Health Of health science and research 2014;4:38-47

6. Garg R, Aggrawal R. An audit of the Blood and component transfusion requests and Utilization pattern in a tertiary care hospital-current trends.International ournal of drug Discoveruand Medical research 2013;1:82-85.

7. Gomathi G, Varghese R, Falleiro JJJ, Lakhani D, Garg S, et al. Audit of use of blood and its components in tertiary care centre in South india.Asian journal of transfusion medicine 2012;6:189-190.

8. WHO (2009) Guidelines and Priniciples for safe blood transfusion practices pp: 25-34 Wells AW, Mounter PJ, Chapman CE, et al. Where does blood go? Prospective observational study of Red cell transfusion in north England. BMJ 2002; 325:803

9. National Blood Data Resource Center. Comprehensive report on blood collection and transfusion in the United States. Bethesda, MD: National Blood Data Resource Center, 2001

10. A quality system model for health care; NCCLS approved guideline (HS1-A). Wayne, PA: National Committee for Clinical Laboratory Standards, 2002 .

11. Sharma S, Sharma P, Tyler LN. Transfusion of Blood and Blood Products: Indications and Complications. Am Fam Physician 2011; 83(6):719-24.

12. Toy PT. Audit and education in transfusion medicine. Vox Sang. 1996; 70:1-5.

13. AABB Technical manual 15 th edition 3rd chapter blood components request and Utilization Pattern in a tertiary care hospital - Current trends.

*Corresponding author:

Dr Amit H. Agravat, Department of Pathology, Pandit Deendayal Upadhyay Government Medical College, Rajkot, India

Phone: +91 9426316176

Email: agravat.katkoriashruti@gmail.com

Financial or other Competing Interests: None. 